\title{
Early detection of cryostorage tank failure using a weight-based monitoring system
}

\author{
Zahava P. Michaelson ${ }^{1}$ (D) - Sai T. Bondalapati ${ }^{1} \cdot$ Selma Amrane $^{1} \cdot$ Robert W. Prosser $^{1} \cdot$ Daniel M. Hill $^{1} \cdot$ Pallavi Gaur $^{1}$. \\ Matt Recio ${ }^{1}$. David E. Travassos ${ }^{1} \cdot$ Mikaela D. Wolfkamp ${ }^{1} \cdot$ Sasha Sadowy ${ }^{1} \cdot$ Colin Thomas $^{1} \cdot$ Eric J. Forman ${ }^{1}$. \\ Zev Williams ${ }^{1}$
}

Received: 7 November 2018 / Accepted: 9 January 2019 / Published online: 5 March 2019

(C) Springer Science+Business Media, LLC, part of Springer Nature 2019

\begin{abstract}
Purpose To study the relationship between liquid nitrogen loss and temperature in cryostorage dewars and develop an earlywarning alarm for impending tank failure.

Methods Cryostorage dewars were placed on custom-engineered scales, and weight and temperature data were continuously monitored in the setting of slow, medium, and fast rate-loss of $\mathrm{LN}_{2}$ to simulate three scenarios of tank failure.

Results $\mathrm{LN}_{2}$ Tank weights and temperatures were continuously monitored and recorded, with a calculated alarm trigger set at $10 \%$ weight loss and temperature of $-185^{\circ} \mathrm{C}$. With an intact tank, a $10 \%$ loss in $\mathrm{LN}_{2}$ occurred in 4.2-4.9 days. Warming to $185^{\circ} \mathrm{C}$ occurred in 37.8-43.7 days, over 30 days after the weight-based alarm was triggered. Full evaporation of $\mathrm{LN}_{2}$ required 36.8 days. For the medium rate-loss simulation, a $10 \%$ loss in $\mathrm{LN}_{2}$ occurred in $0.8 \mathrm{~h}$. Warming to $-185^{\circ} \mathrm{C}$ occurred in $3.7-4.8 \mathrm{~h}$, approximately $3 \mathrm{~h}$ after the weight-based alarm was triggered. For the fast rate-loss simulation, a 10\% weight loss occurred within $15 \mathrm{~s}$, and tanks were depleted in under $3 \mathrm{~min}$. Tank temperatures began to rise immediately and at a relatively constant rate of $43.9^{\circ} \mathrm{C} / \mathrm{h}$ and $51.6^{\circ} \mathrm{C} / \mathrm{h}$. Temperature alarms would have sounded within 0.37 and $0.06 \mathrm{~h}$ after the breech.

Conclusions This study demonstrates that a weight-based alarm system can detect tank failures prior to a temperature-based system. Weight-based monitoring could serve as a redundant safety mechanism for added protection of cryopreserved reproductive tissues.
\end{abstract}

Keywords Cryostorage $\cdot$ Cryopreservation $\cdot$ Embryos $\cdot$ Oocytes $\cdot$ Weight

\section{Introduction}

Safeguarding cryopreserved embryos and gametes is one of the critical responsibilities of fertility centers and tissue banks. Cryopreservation in liquid nitrogen $\left(\mathrm{LN}_{2}\right)$ preserves the viability of biological materials by halting their molecular processes [1], enabling their long-term storage [2-4]. Failure to maintain adequate $\mathrm{LN}_{2}$ within a storage tank can result in stored samples thawing and, ultimately, in their total loss. In

Electronic supplementary material The online version of this article (https://doi.org/10.1007/s10815-019-01402-3) contains supplementary material, which is available to authorized users.

Zev Williams

zw2421@ columbia.edu

1 Columbia University Fertility Center, 5 Columbus Circle, PH, New York, NY 10019, USA the case of stored embryos or eggs, such a loss can be catastrophic for affected patients, their partners, and the fertility center [5]. Thus, it is of utmost importance to develop and perfect methods to prevent the depletion of $\mathrm{LN}_{2}$ from cryopreservation tanks.

Cryopreserved samples are typically stored in cryostorage tanks that utilize $\mathrm{LN}_{2}$ to maintain a temperature of $-196{ }^{\circ} \mathrm{C}$ [6]. Small storage tanks hold $\sim 30-75 \mathrm{~L}$ of $\mathrm{LN}_{2}$ within double-walled, insulated metal containers with vacuum chambers between their two walls. Incidents of unintentional thaws of cryopreserved tissues are usually caused by one of three mechanisms [7]: (A) slow rate-loss: in the case of "tank abandonment," the cryopreservation tank functions normally and $\mathrm{LN}_{2}$ evaporates at the expected rate, but the tank is not refilled in a timely manner, allowing $\mathrm{LN}_{2}$ to be depleted and the temperature to rise; (B) medium rate-loss: a breach to the insulation of the tank, due to either damage to the vacuum seal or someone forgetting to replace the tank's foam 
insulation, leads to a faster than normal rate of $\mathrm{LN}_{2}$ evaporation and the supply being depleted prior to the next scheduled refilling; or (C) fast rate-loss: a catastrophic tank failure causes direct leakage of $\mathrm{LN}_{2}$.

Existing methods to prevent unintentional thawing of cryopreserved tissues consist of a combination of manual checks and automated monitoring systems [8]. The most common form of automated monitoring involves using temperature probes, which are placed within tanks and communicate wirelessly to a central monitoring station. When temperatures rise, the probes send an audible alert and, typically, automatically call a predetermined phone number. While this system is helpful, it has some inherent limitations. Firstly, temperatures only start to rise once the $\mathrm{LN}_{2}$ is nearly depleted. There is, in turn, a very limited timeframe for which the $\mathrm{LN}_{2}$ can be replaced before the specimens are completely lost. Secondly, since the sensors note a rise in temperature, the lowest possible storage temperature will have, by definition, been passed before the alarm is sounded. Thirdly, this method requires that sensitive electronic equipment be placed within the harsh conditions of a cryopreservation tank, thereby limiting the lifespan of the probes and increasing the cost for monitoring. Finally, because current monitors require that probes be placed within the $\mathrm{LN}_{2}$, the introduction of a second probe for additional monitoring of samples is cumbersome and represents a replicative rather than truly redundant method. There is, as such, a need for a monitoring method that is redundant to the temperature probe, is positioned externally to the tank, and provides early detection of impending tank failure to safeguard the integrity of cryopreserved tissues.

Regular weight measurements to determine $\mathrm{LN}_{2}$ evaporation rates have been used in the assessment of cryostorage tank viability, but such efforts have yet to be applied to in-use specimen storage tanks where improved quality control practices are needed [8]. We hypothesized that continuous observation of tank weight could be a simple, safe, low-cost method for real-time, automated monitoring of cryostorage tanks. In contrast to temperature alarms, weight-based alarms can be calibrated to sound when a given proportion of $\mathrm{LN}_{2}$ is lost. An alert would thus be triggered before the $\mathrm{LN}_{2}$ supply is completely depleted and the tank's temperature rises, giving staff more time to refill the tank or transfer samples to a different tank. The scale would also be external to the tank, thereby obviating the need for electronics that could withstand the supercooled environment within the tanks. Finally, a weight-based alarm system could provide a redundancy to the existing safety mechanisms.

Here, we tested the ability of custom-built, web-enabled scales to monitor cryostorage dewars in slow, medium, and fast rate-loss tank failure simulations and demonstrate that a weight-based system provides an effective early-warning and redundant safeguard for cryopreserved specimens.

\section{Materials and methods}

\section{Scale design}

For all simulations, custom-engineered and manufactured scales were used to measure and record tank weight. The scales had a $400 \mathrm{lb}$. capacity and data output capabilities, and were attached to a terminal that was connected via Ethernet to a central computer monitoring station. TCP Wedge with custom scripts was used for collection of six fields of data from the networked device. A programmable alarm system was used to record real-time weight information (Fig. 1). Alarms were set to trigger after a $10 \%$ weight loss. All experiments were performed with $22.4 \mathrm{~L}$ MDD 93/42/EEC compliant passive cryostorage tanks (MVE xc 22/5; Chart Biomedical) containing empty canisters and no patient samples. The tanks involved in this study were fully functioning, in-use tanks made available by consolidating their samples into other tanks. Tanks were placed on the scales and the scales were tared. The tanks were then filled with $\mathrm{LN}_{2}$, and topped-off until the temperature reached equilibrium and $\mathrm{LN}_{2}$ boiling ceased. The temperature within the tanks was simultaneously monitored with probes (Safepoint Scientific) placed near the top of the tanks with calculated alarms using a $-185{ }^{\circ} \mathrm{C}$ threshold, as per

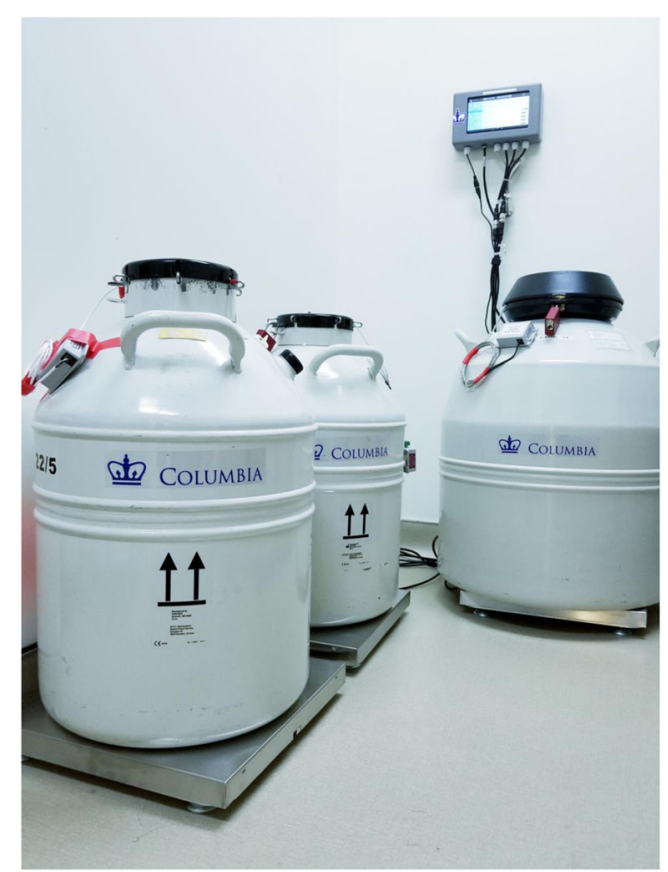

Fig. 1 Experimental set-up. $\mathrm{LN}_{2}$ dewars equipped with temperature probes were placed on scales. Weights were recorded continuously in real-time via relay to an Ethernet-connected monitoring unit 
standard operating practice. Ambient room temperatures were $23-25{ }^{\circ} \mathrm{C}$.

\section{Tank failure scenarios}

For the "slow rate-loss" simulations, designed to mimic what would occur if a fully functioning tank were left unattended, two $\mathrm{LN}_{2}$ dewars (Tank A and Tank B) were filled to capacity with $\mathrm{LN}_{2}$, topped-off until temperature reached equilibrium and $\mathrm{LN}_{2}$ boiling ceased, and then left undisturbed while the tank weights and temperatures were monitored continuously, in usual operating conditions. $\mathrm{LN}_{2}$ was allowed to evaporate at the normal rate until all $\mathrm{LN}_{2}$ had evaporated and temperature returned to room temperature (RT). For the "medium rateloss" simulation, designed to mimic what would occur if the insulating capacity of a tank were compromised, the insulating foam core of the tank neck was removed and the insulating vacuum was eliminated by the creation of a $1 / 16^{\prime \prime}$ hole in just the outer tank wall. Dewars were then filled to capacity with $\mathrm{LN}_{2}$, topped-off until the temperature reached equilibrium and $\mathrm{LN}_{2}$ boiling ceased and then left alone while the tank weight and temperature were monitored continuously. For the "fast rate-loss" simulation, designed to mimic what would occur if a catastrophic tank breech were to cause $\mathrm{LN}_{2}$ to rapidly spill from the tanks, the 1/16" hole was continued through the inner tank wall. Dewars were then filled to capacity with $\mathrm{LN}_{2}$, topped-off until the temperature reached equilibrium and $\mathrm{LN}_{2}$ boiling ceased, and $\mathrm{LN}_{2}$ was released at a rate of $0.15 \mathrm{~L} / \mathrm{s}$. All simulations were performed in duplicate.

a

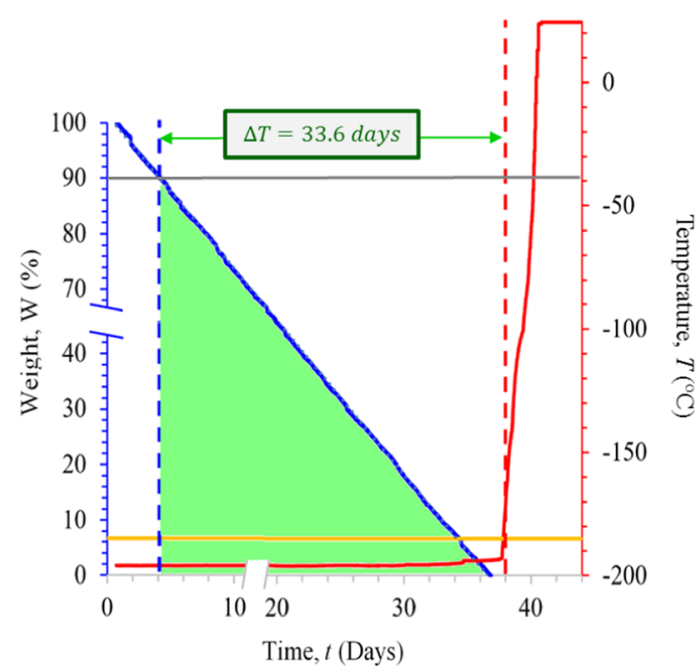

Fig. 2 Results of the slow rate-loss trial. a The decrease in $\mathrm{LN}_{2}$ weight (as a percentage of starting weight; blue line), and the corresponding increase in temperature $\left({ }^{\circ} \mathrm{C}\right)$ over time (measured in days; red line) are shown. Thresholds for detecting a $10 \%$ weight loss and a temperature of $-185^{\circ} \mathrm{C}$ are indicated by the gray and yellow lines, respectively. The interval between the detection of $10 \%$ weight drop and a rise in temperature to $-185^{\circ} \mathrm{C}$ is 33.6 days and is indicated as the distance between the dashed blue and red lines. The rate of weight loss can be described by the formula

\section{Results}

Weight and temperature data collected during the simulations of slow rate-loss from Tanks A and B are presented in Fig. 2a, $\mathrm{b}$, respectively, and in Table 1 . The time required for a $10 \%$ loss in $\mathrm{LN}_{2}$ was 4.2 and 4.9 days for Tanks $\mathrm{A}$ and $\mathrm{B}$, respectively (Table 1). Warming to $-185{ }^{\circ} \mathrm{C}$ occurred in 37.8 and 43.7 days for Tanks A and B, respectively. Thus, the weightbased system was able to detect a $10 \%$ weight loss between 33.7 and 38.8 days before the temperature alarm threshold was reached (Fig. 2a, b, Table 1). The rate of $\mathrm{LN}_{2}$ loss was $1.05 \mathrm{~kg} /$ day and $0.89 \mathrm{~kg} /$ day for Tanks A and B, respectively. Because Tank B retained $\mathrm{LN}_{2}$ better, Tank A was used for subsequent studies to minimize the differences between weight- and temperature-based monitoring. Full evaporation of Tank A required 36.8 days (Fig. 2a). Tank temperatures, as recorded by a temperature probe placed a few centimeters below the tank neck, remained stable until $\mathrm{LN}_{2}$ was $>95 \%$ evaporated (Fig. 2b). Thereafter, the rate of warming was nearly constant occurred at a rate of and $60.5^{\circ} \mathrm{C} /$ day (Fig. b). The rate of weight loss for the intact tank can be described by the formula $W=-2.778 t+101.48$, where $W$ is the weight as a percentage of the full tank and $t$ is the time in days $\left(R^{2}=\right.$ 0.9999).

For the medium rate-loss simulation, the time required for a $10 \%$ loss in $\mathrm{LN}_{2}$ was $0.8 \mathrm{~h}$ for runs 1 and 2 (Table 1, Fig. 3a). Warming to $-185^{\circ} \mathrm{C}$ occurred in 3.7 and $4.8 \mathrm{~h}$ for runs 1 and 2 , respectively (Table 1). Thus, the weight-based system was able to detect a $10 \%$ weight loss between 3.0 and $4.0 \mathrm{~h}$ before b

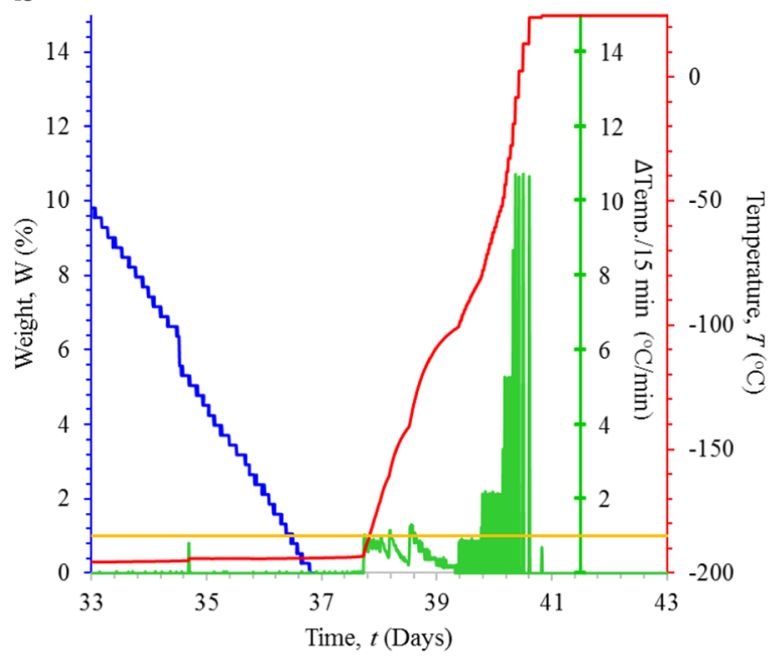

$W=-2.778 t+101.48$ where $W$ is the $\mathrm{LN}_{2}$ weight (as a percentage of total) and $t$ is the time (measured in days; $R^{2}=0.9999$ ). b Expansion of the period of time between days 33 and 43 shows a slight time interval between when the tank fully empties (blue line) and when the temperatures begin to rise (red line). The threshold for triggering the $-185^{\circ} \mathrm{C}$ temperature alarm is indicated in yellow. The rate of temperature increase, shown as the change in temperature $\left({ }^{\circ} \mathrm{C}\right)$ for each 15 -min interval, is indicated in green 
Table 1 Time require for a $10 \%$ drop in weight $\mathrm{LN}_{2}$ from a full tank, the time required for temperatures to rise to $-185^{\circ} \mathrm{C}$ and the interval between those two times for each of the experimental conditions

\begin{tabular}{|c|c|c|c|c|c|c|}
\hline & $\begin{array}{l}\text { Slow rate } \\
\text { Tank A (Days) }\end{array}$ & $\begin{array}{l}\text { Slow rate } \\
\text { Tank B (Days) }\end{array}$ & $\begin{array}{l}\text { Medium rate } \\
\text { Run } 1 \text { (Hours) }\end{array}$ & $\begin{array}{l}\text { Medium rate } \\
\text { Run } 2 \text { (Hours) }\end{array}$ & $\begin{array}{l}\text { Fast rate Run } \\
1 \text { (Hours) }\end{array}$ & $\begin{array}{l}\text { Fast rate Run } \\
2 \text { (Min) }\end{array}$ \\
\hline Time to $10 \% \downarrow$ wt & 4.2 & 4.9 & 0.8 & 0.8 & NA & NA \\
\hline Time to $-185^{\circ} \mathrm{C}$ & 37.8 & 43.7 & 3.7 & 4.8 & 0.37 & 0.06 \\
\hline $\begin{array}{l}\Delta 10 \% \downarrow \text { wt } \\
\quad \text { and }-185^{\circ} \mathrm{C}\end{array}$ & 33.7 & 38.8 & 3.0 & 4.0 & NA & NA \\
\hline
\end{tabular}

the temperature alarm threshold was reached (Fig. 3a, Table 1). The rate of $\mathrm{LN}_{2}$ loss was significantly higher than in the trials using the uncompromised tanks and was the fastest for the loss of the initial $50 \%$ of $\mathrm{LN}_{2}$ : the first $50 \%$ of the volume was lost in 4.3 and $4.7 \mathrm{~h}$ for runs 1 and 2, respectively. The remaining $50 \%$ of tank volume was lost in 7.5 and $7.8 \mathrm{~h}$ for runs 1 and 2, respectively (Fig. 3a and Supplementary Fig. 1). In contrast to the results of the uncompromised tank study, temperatures in the compromised tanks began rising much sooner-just about 1 hour after $10 \%$ of $\mathrm{LN}_{2}$ volume was lost. The rate of temperature rise was bi-phasic with a slower rate of warming $\left(3{ }^{\circ} \mathrm{C} / \mathrm{h}\right.$ and $2.3{ }^{\circ} \mathrm{C} / \mathrm{h}$ for runs 1 and 2 , respectively) while $\mathrm{LN}_{2}$ was present and a much faster rate of warming $\left(48^{\circ} \mathrm{C} /\right.$ $\mathrm{h}$ and $58.3{ }^{\circ} \mathrm{C} / \mathrm{h}$ for runs 1 and 2, respectively) after $\mathrm{LN}_{2}$ was depleted (Fig. 3a and Supplementary Fig. 1). The rate of weight loss for the breeched tank can be approximated by the formula $W=0.4447 t^{2}-13.661 t+100.07$ where $W$ is the weight as a percentage of the full tank and $t$ is the time in hours $\left(R^{2}=\right.$ 0.9997, calculated from run 1).

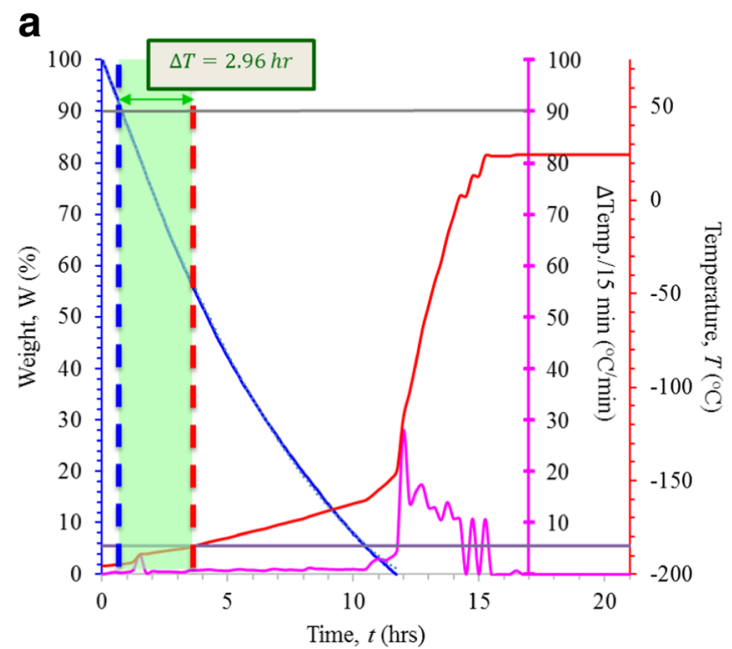

Fig. 3 a Results of the medium rate-loss trial. The decrease in $\mathrm{LN}_{2}$ weight (as a percentage of starting weight; blue line), and the corresponding increase in temperature $\left({ }^{\circ} \mathrm{C}\right)$ over time (measured in hours; red line) are shown. Thresholds for detecting a $10 \%$ weight loss and rise in temperature to $-185^{\circ} \mathrm{C}$ are indicated by the gray and purple lines, respectively. The interval between the detection of $10 \%$ weight drop and a rise in temperature to $-185^{\circ} \mathrm{C}$ was approximately $3 \mathrm{~h}$ and is indicated as the distance between the dashed blue and red lines. The rate of weight loss
For the fast rate-loss simulation, a $10 \%$ weight loss occurred within $15 \mathrm{~s}$ and tanks were completely depleted in under 3 min (Fig. 3b, Table 1, Supplementary Fig. 2). As shown in Fig. 3b, tank temperatures began to rise immediately and at a relatively constant rate of $43.9{ }^{\circ} \mathrm{C} / \mathrm{h}$ and $51.6^{\circ} \mathrm{C} / \mathrm{h}$. Temperature alarms would have sounded within 0.37 and $0.06 \mathrm{~h}$ after the breech (Fig. 3b, Table 1, Supplementary Fig. 2).

\section{Discussion}

Existing methods to protect cryopreserved reproductive tissue are reliable and failures are extremely rare [5]. However, as recent cases have highlighted, catastrophic failures are still possible. Thus, there is a need to reevaluate safeguards and consider innovative quality management practices [8].

This study demonstrates that a weight-based, automated alarm system can detect tank failures prior to a temperature-

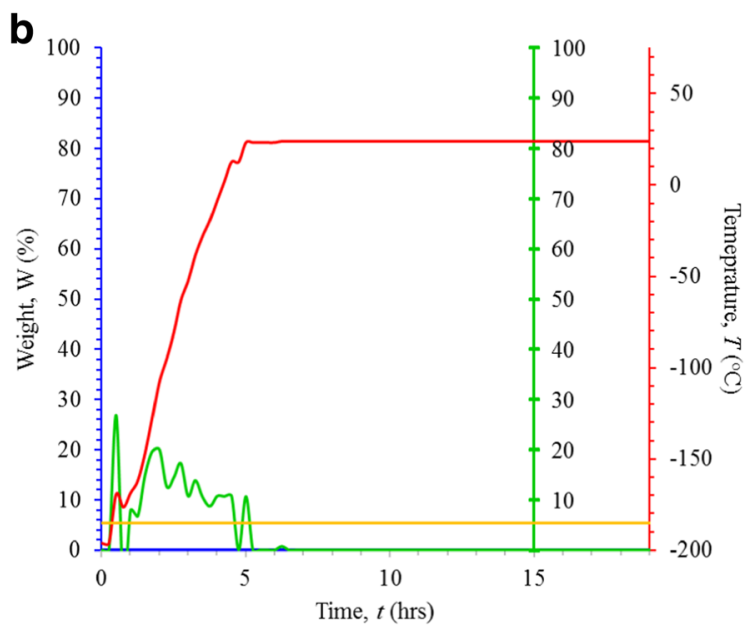

can be described by the formula $W=0.4447 t^{2}-13.661 t+100.07$ (where $W$ represents weight, measured as a percentage of total and $t$ represents time, measured in hours; $\left.R^{2}=0.9997\right)$. The rate of change of temperature, measured in 15 -min intervals and recorded as ${ }^{\circ} \mathrm{C} / \mathrm{min}$, is shown in magenta. b Results of the rapid rate-loss trial. Thresholds for detecting a rise in temperature to $-185^{\circ} \mathrm{C}$ are indicated by the yellow lines. The rate of change of temperature, measured in 15-min intervals and recorded as ${ }^{\circ} \mathrm{C} / \mathrm{min}$, is shown in green 
based alarm system. The time interval between the weightbased and temperature-based alarms varies depending on the threshold set for each and the rapidity and nature of the loss. Using standard temperature alarm settings and a $10 \%$ weight loss threshold, the weight-based alarm detected anomalies as far as 33 days in advance of a temperature rise. Such a system directly correlates and more precisely determines $\mathrm{LN}_{2}$ level measurements. In cases where there was a higher rate of $\mathrm{LN}_{2}$ loss, the interval was smaller.

When the integrity of the vacuum insulation was left intact, tank temperatures remained below $-190{ }^{\circ} \mathrm{C}$ until the $\mathrm{LN}_{2}$ was essentially completely depleted (Fig. 2a) whereas, when the insulating capacity was breached, temperatures rose above the critical point of $-185^{\circ} \mathrm{C}$ about 8 days before depletion, when $60 \%$ of the $\mathrm{LN}_{2}$ supply still remained (Fig. 3a). This is likely because the intact vacuum layer allowed lingering nitrogen vapor to maintain low tank temperatures during evaporation, while that ability failed when ambient air entered the annular surrounding the inner tank. This is of practical implication because the normal buffer time available to replenish $\mathrm{LN}_{2}$ is drastically and disproportionately shortened in cases of an abrupt loss of insulating capacity.

It should be noted that the anticipated application of this technology is not as a replacement for existing safety monitoring systems, including temperature, but as an additional and redundant safety mechanism. Since existing tanks and their probes can be placed directly on scales, this technology can be readily adopted. For centers that place tanks on wheeled dollies, the scale can be designed to fit onto the dolly and beneath the dewar, or integrated into the dolly itself. In cases of cryopreservation of less critical tissues (e.g., animal cell lines), a weight-based alarm system may be a costeffective alternative to temperature-based alarms. Given the ability to accurately record the rate of loss of $\mathrm{LN}_{2}$, the scales can also be used for QC testing of tanks, including the qualification of new tanks [8], to confirm that they maintain $\mathrm{LN}_{2}$ as specified. In clinical scenarios, as with temperature alarms, QC procedures with periodic testing of the scale alarm would be necessary.

There were several limitations to this study. The first is that it was conducted with a single brand and make of dewar. There is likely variation in the rate of $\mathrm{LN}_{2}$ loss and temperature rise depending on the particular type, model, and insulation integrity of the dewar. The tank size used $(22.4 \mathrm{~L})$ was among the smaller sizes available, and the specific kinetics would likely differ depending on the tank size. The time interval between when weight-based and temperature-based alarms are triggered also depends on where within the tank the temperature probe is placed. Nonetheless, the overall finding that weight anomalies will proceed temperature anomalies is likely to hold true with dewars of differing size and manufacturer. In our experiments, temperature probes were placed near the top of the tank. Placing the temperature probe in a lower position within the tank would undoubtedly result in even more $\mathrm{LN}_{2}$ lost before a temperature probe would detect a change. A similar effect would occur if warmer threshold temperature (e.g., $-175^{\circ} \mathrm{C}$ ) had been selected [8]. In order to minimize the interval between the weight and temperaturebased alarms, the threshold selected for triggering the temperature alarm in this study was $-185^{\circ} \mathrm{C}$. In clinical practice, the normal rate of evaporation of $\mathrm{LN}_{2}$ from each tank would need to be determined in order to select an appropriate threshold weight at which to trigger an alarm.

Performance of the scale-based system in real-world conditions and over time will need to be evaluated, but should significantly improve the response time interval as shown in this study. Any reduction in the interval between alarm and response time could prove critical in limiting the possibility of compromising samples.

\section{Conclusions}

Our data show that continuous monitoring of cryostorage tank weight enabled detection of anomalies in advance of temperature rises. As part of an automated alarm system, this would provide earlier detection of a problem and thereby give increased time to remedy the situation before cryopreserved reproductive tissue is lost. When used in conjunction with existing safety systems, including temperature monitoring, a weight-based system would also provide a redundant safety mechanism. While risk can never be completely eliminated, our hope is that by adding additional safeguards to the existing manual and automated safety mechanisms, cryopreservation can become even safer.

Acknowledgements The authors thank the members of Columbia University Fertility Center for their assistance in conducting the trial.

Funding information $\mathrm{ZW}$ is partially supported through funding from the National Institutes of Health (grants HD068546 and U19CA179564). $\mathrm{ZW}$ is listed as an inventor on patent applications filed by Columbia University relating to this system.

Publisher's note Springer Nature remains neutral with regard to jurisdictional claims in published maps and institutional affiliations.

\section{References}

1. Cohen J, Inge KL, Wiker SR, Wright G, Fehilly CB, Turner TGJ. Duration of storage of cryopreserved human embryos. J In Vitro Fert Embryo Transf. 1988;5:301-3.

2. Glenister PH, Whittingham DG, Lyon MF. Further studies on the effect of radiation during the storage of frozen 8-cell mouse embryos at -196 degrees C. J Reprod Fertil. 1984;70:229-34.

3. Goldman KN, Kramer Y, Hodes-Wertz B, Noyes N, McCaffrey C, Grifo JA. Long-term cryopreservation of human oocytes does not increase embryonic aneuploidy. Fertil Steril. 2015;103:662-8. 
4. Ueno S, Uchiyama K, Kuroda T, Yabuuchi A, Ezoe K, Okimura T, et al. Cryostorage duration does not affect pregnancy and neonatal outcomes: a retrospective single-centre cohort study of vitrifiedwarmed blastocysts. Reprod BioMed Online. 2018;36:614-9.

5. Bulletin A. ASRM statement on second report of storage tank failure. In: ASRM Office of Public Affairs Vol 20, 2018.

6. Tomlinson M, Morroll D. Risks associated with cryopreservation: a survey of assisted conception units in the UK and Ireland. Hum Fertil (Camb). 2008;11:33-42.
7. Pomeroy KO. Liquid nitrogen storage tank failure: can we improve the current system? Fertil Steril, www.fertilstertdialog.com, May 19, 2018

8. Schiewe MC, Freeman M, Whitney JB, VerMilyea MD, Jones A, Aguirre $\mathrm{M}$ et al. Comprehensive assessment of cryogenic storage risk and quality management concerns: best practice guidelines for ART labs. J Assist Reprod Genet 2018; 35(12):in press. https://doi. org/10.1007/s10815-018-1310-6. 